\title{
Tensiones entre una ruralidad productiva y otra residencial: EI caso del partido de Exaltación de la Cruz, Buenos Aires, Argentina
}

\author{
Clara Craviotti*
}

\begin{abstract}
This paper analyses the tensions generated from the expansion of residential undertakings in rural areas as well as the way in which such tensions are expressed at a spatial level. The study takes as an empirical reference an area relatively close to the city of Buenos Aires, the province of Exaltación de la Cruz. The methodology used combines the analysis of secondary data with information obtained from surveys. In the particular case chosen, the heterogeneity of the rural space is kept and is actually increased. The revitalisation of aviculture within the context of the change of macroeconomic conditions defies the expansion of residential usage of the land. The conclusion is there is a need for new forms of regulation in terms of instruments and agreement instances where the different players could participate in order to find a less problematic way to link the "new" and the "old" rurality of the province.
\end{abstract}

Keywords: Socio-territorial changes, new rurality, peri-urban areas

\section{Resumen}

El artículo se centra en el análisis de las tensiones que genera la expansión de emprendimientos residenciales en el medio rural, así como en la expresión que dichas tensiones adquieren a nivel espacial. Toma como referencia empírica un área relativamente cercana a la ciudad de Buenos Aires, el partido de Exaltación de la Cruz. El enfoque metodológico combina el análisis de datos secundarios con información proveniente de entrevistas; en el caso analizado, la heterogeneidad del espacio rural persiste, y además se incrementa. La revitalización de la avicultura en el contexto del cambio de las condiciones macro-económicas desafía la expansión de los usos residenciales del suelo. En conclusión existe la necesidad de nuevas formas de regulación, en términos de instrumentos y de instancias de concertación donde participen diferentes actores, con el fin de encontrar formas menos problemáticas de vinculación entre la "nueva" y la "vieja" ruralidad del partido.

Palabras clave: Cambios socioterritoriales, nueva ruralidad, áreas periurbanas

* Universidad de Buenos Aires. Correo-e: ccraviotti@yahoo.com 


\section{Introducción}

Ya desde inicios de los setenta, pero más definidamente en los noventa, comenzaron a expandirse en la provincia de Buenos Aires nuevas formas de uso del espacio rural basadas en aspectos no ya productivos sino residenciales: las urbanizaciones cerradas. Countries o clubes de campo primero, barrios privados y chacras después, van dando cuenta de nuevas formas de apropiación del espacio pero también de "mercantilización" de lo rural (Marsden, 1998), ligadas a nuevas necesidades de los habitantes urbanos.

Este fenómeno, a veces definido como la "suburbanización de las elites" (Torres, 2001), es tardío en la Argentina si se lo compara con otros países latinoamericanos. En realidad preexistió a ese proceso de suburbanización uno de asentamiento de las clases populares, ligado al modelo de desarrollo entonces imperante. En efecto, en el contexto de la industrialización sustitutiva de importaciones se favoreció la radicación de esos sectores en la periferia de la ciudad de Buenos Aires, a partir de una política de loteos accesibles y el subsidio al transporte ferroviario. Esos asentamientos condicionarían aquellos posteriormente protagonizados por fracciones de las clases medias y altas, dramatizando los contrastes socioespaciales.

Es así como la expansión de los countries en los noventa no puede ser entendida sin la consideración de los cambios producidos en el modelo de desarrollo de la Argentina, donde pierden protagonismo las actividades industriales en desmedro de aquellas vinculadas con los servicios, siendo precisamente algunos sectores sociales ligados a esos servicios los que encarnan estas nuevas formas de hábitat.

Es un lugar común la idea de que este tipo de asentamientos generan profundos impactos en el entorno circundante, en especial en lo que atañe al empleo, por tratarse de sectores de cierto poder adquisitivo que demandan un conjunto de bienes y servicios personales. Sin entrar a cuestionar esa visión -que con ser verosímil, no parece haber sido cabalmente medida-, en este trabajo me introduciré en una temática escasamente analizada desde las ciencias sociales: la de las tensiones que esa expansión genera desde el punto de vista de la estructura agraria preexistente en las áreas objeto de la expansión. Para ello tomaré como 
referencia empírica, un área relativamente cercana a la ciudad de Buenos Aires en donde los usos residenciales del suelo han crecido en los últimos años. ${ }^{1}$

Como analizaré posteriormente, las tensiones entre una dinámica productiva y residencial no tienen un correlato necesario en la oposición entre actores locales y extralocales. Tienen sí un polo claramente definido, el de los sectores sociales vinculados con determinadas actividades agrarias por un lado, y por el otro, un difuso conglomerado de actores vinculados con o beneficiados por la expansión inmobiliaria. Dichas tensiones revelan que el ámbito local se convierte en el escenario privilegiado donde se conjugan las diferentes fuerzas de cambio de lo rural, de acuerdo con las cambiantes y heterogéneas necesidades propias de sociedades con cierta diversificación de su base social y ocupacional.

\section{Antecedentes}

En Argentina, la problemática de la expansión de usos residenciales en el medio rural en los noventa fue en gran medida analizada desde la óptica urbana. Se la consideró como una forma de segregación espacial que fomentaba la fragmentación social (Torres, 2001; Svampa y González-Bombal, 2001). En esa literatura, las formas de asentamiento constituyen una clara expresión de las transformaciones experimentadas por la estructura social argentina; inciden en las modalidades de vinculación social, y éstas, a su vez, en el grado de integración de la sociedad:

[...] la proliferación de esta nueva forma de habitar muestra el pasaje a una matriz societal más rígida y jerárquica que la que caracterizara a la Argentina durante gran parte del siglo xx; una inflexión que certifica la entrada a una nueva época, en la cual las desigualdades se multiplican en todos los registros y la privatización general de la sociedad genera nuevas realidades [...] Así, si las lecturas acerca de la nueva pobreza, en un primer movimiento, pusieron el énfasis en la brecha que en términos de consumo se abría entre los diferentes sectores de la clase media, ahora en un segundo movimiento, es necesario dar cuenta de una brecha mayor que se abre en términos de estilos de vida y modelos de socialización (Svampa, 2001: 45-46).

${ }^{1}$ La información en que se basa el presente artículo fue relevada en el marco del proyecto PIP CONICET Identidades agrarias en transformación. La pluriactividad en los pequeños y medianos productores de la región pampeana, dirigido por Guillermo Neiman. Las entrevistas en profundidad a informantes clave y a productores fueron efectuadas entre abril y julio de 2005. 
El proceso ha sido descrito como el desplazamiento de un modelo de "ciudad abierta", básicamente europeo, centrado en la noción de espacio público y en valores como la ciudadanía política y la integración, a un régimen de "ciudad cerrada", según el modelo norteamericano, marcado por la afirmación de una ciudadanía "privada”, que refuerza la fragmentación social (Svampa y González-Bombal, 2001). En términos espaciales, el proceso adquiere particular relevancia en la periferia externa de la aglomeración Gran Buenos Aires -lo que se ha dado en llamar el tercer "cordón" del conurbano- (Torres, 2001).

En esos estudios se hace alusión a las tensiones entre nuevos $\mathrm{y}$ antiguos residentes vinculadas con las dificultades de circulación o de traslado que generan estas nuevas fronteras o "interrupciones" de la trama urbana, así como a la marcada diferenciación entre las franjas "ganadoras" de las clases de los servicios, protagonistas de estos emprendimientos y los que constituyen sus servidores, un amplio proletariado de servicios (Svampa, 2001). No se analizan las implicaciones de la expansión residencial sobre las actividades productivas desarrolladas en el medio rural.

¿Cuál es la visión desde los estudios rurales? Existe una importante literatura preocupada por la evolución de las modalidades productivas en las áreas periurbanas, que luego incorpora más definidamente la temática de la irrupción de las urbanizaciones cerradas en dichos espacios. ${ }^{2}$

En relación con la actividad agraria, se señala que la elevación del valor de la tierra provocada por el desarrollo de emprendimientos residenciales disloca los usos agrícolas tradicionales de los espacios rurales. El valor de la tierra se eleva de tal manera que el costo de oportunidad de una ocupación agrícola tradicional se inviabiliza en favor de otros usos más rentables o del propio no uso más inmediato. Chiozza, Carballo y Torcchia (2001) precisan que los métodos de producción tradicional se vuelven insostenibles en ese contexto, por lo que se produce una intensificación productiva y un cambio en la estructura social agraria, incrementándose el peso de los empresarios.

Desde el punto de vista del empleo en áreas rurales, los efectos de la expansión residencial serían similares a los asociados con la expansión del turismo, conllevando posibilidades labora-

2 Para un análisis de la evolución de los estudios periurbanos con énfasis en la temática ambiental, véase el trabajo de A. Barsky (2005). 
les para sujetos que presentan una 'empleabilidad' menor en un mercado laboral agropecuario (Barros et al., 2005). ${ }^{3}$

Adoptando una mirada que trasciende el caso argentino, encontramos que en términos generales los trabajos que aluden a la expansión de los usos residenciales del espacio rural se inscriben en dos enfoques teóricos: el de la nueva ruralidad y el del posproductivismo.

El primero de ellos surgió en América Latina a principios de los noventa, si bien es probable que haya sido influido por los desarrollos teóricos originados en las sociedades capitalistas avanzadas centrados en la "agricultura a tiempo parcial", la "pluriactividad" y la "multifuncionalidad" de la empresa agropecuaria familiar (Kay, 2005). La perspectiva de la nueva ruralidad pone énfasis en la revalorización de los espacios rurales, que pasan a ser "consumidos" por los habitantes urbanos, a partir de ciertas características diferenciales que les son atribuidas -la tranquilidad, un ambiente menos contaminado. También pone el acento en la diversificación del empleo en las áreas rurales y en la creciente interrelación rural-urbana, puesta de manifiesto en la pluriactividad de los productores agropecuarios y sus familias, que desarrollan otras actividades además de la producción agropecuaria, y en la presencia de nuevos residentes y/o agentes productivos de orígenes urbanos.

Siguiendo a Riella y Romero (2003), para hablar de la emergencia o no de una "nueva ruralidad" se requiere constatar empíricamente en las áreas bajo análisis la existencia de un grado importante de diversificación del empleo y de redes de relaciones sociales no basadas fundamentalmente en el eje de las relaciones agrarias. Frente a estos fenómenos habrá que preguntarse en qué medida éstos son producto de cambios recientes $\mathrm{u}$ obedecen a viejas dinámicas dejadas de lado en los análisis previos.

El enfoque sobre la nueva ruralidad constituye, sin embargo, un cuerpo analítico sumamente heterogéneo. Mientras algunos autores optan por una definición amplia, considerando como ma-

\footnotetext{
${ }^{3}$ La expansión del turismo en áreas rurales posee un fuerte impacto en el empleo, en particular en el de tipo no calificado (Acuña y Ruiz, 1999). En el nivel más micro de los establecimientos agropecuarios, la actividad turística tendría un efecto potenciador sobre otras actividades agrarias, facilitando la participación de la familia rural en las actividades (Programa Raíces. Martínez et al., 1999). El análisis de casos concretos ha relativizado, sin embargo, los impactos positivos sobre la dimensión productiva, si bien muestra una ampliación de las competencias laborales de las familias y de sus marcos de sociabilidad a partir de esa "nueva" actividad. Un análisis de la temática se encuentra en Craviotti (2002).
} 
nifestaciones de la nueva ruralidad tanto las actividades agrarias tradicionales de producción de commodities como la producción de alimentos destinados a nichos de mercado y las actividades no agrícolas desarrolladas en el espacio rural, otros optan por una definición más restringida, considerando como tales las actividades compensadoras -por contraposición a las productivas- generadas a partir de las necesidades que los habitantes urbanos buscan satisfacer en el ámbito rural. ${ }^{4}$

"Como el enfoque de la nueva ruralidad, el posproductivismo habla del consumo de los espacios rurales en función de las características diferenciales de éstos, a lo que agrega la consideración de otras tendencias actualmente identificables [...]". En la actividad agraria y en las políticas hacia el sector, que comenzaron a tomar cuerpo desde mediados de los ochenta en los países europeos. Tanto la preocupación por la calidad de los alimentos como la que apunta a una regulación de la actividad agraria teniendo en cuenta criterios ambientales, suponen una puesta en cuestión del ethos productivista hasta entonces predominante. Un elemento distintivo es que mientras el enfoque de la nueva ruralidad presta un interés particular a los vínculos entre lo rural y lo urbano, el del posproductivismo hace referencia a la posible existencia de tensiones entre ambas realidades.

Esta perspectiva considera que la producción agrícola como eje constitutivo de lo rural y las formas de regulación asociadas han entrado en crisis en los países avanzados. Los ámbitos rurales actuales son mucho más "polivalentes" en términos de actores y usos del espacio (Marsden, 1998). Cuatro esferas influyen actualmente en el desarrollo de los espacios rurales: la de los mercados alimentarios masivos, la de los centrados en la calidad, los desarrollos relacionados con la agricultura (e.g.: el turismo rural), y los desarrollos no agrícolas (explotaciones mineras, basurales, establecimientos militares, parques industriales). No sólo es necesario identificar estas esferas y sus posiciones relativas en los diferentes espacios rurales -aspecto también indicado por el enfoque de la nueva ruralidad-, sino que también hay que evaluar el grado de complementariedad y conflicto que existe entre las diferentes esferas. No se trata de fuerzas simplemente económicas; poseen instrumentos regulatorios asociados. ${ }^{5}$

${ }^{4}$ Como exponente de la primera corriente, véase el trabajo de Del Grossi y Da Silva (2002); la segunda variante de la neorruralidad es adoptada por Barros et al., (2005).

${ }^{5}$ Se ha objetado que el término posproductivismo constituya una especie de 'paraguas' que permite abarcar los diferentes fenómenos hoy presentes en los espacios rurales, proponiéndose como alternativa el de multifunctional transition (Holmes, 
En trabajos más recientes se alude a las diferentes representaciones de lo rural que poseen actores sociales de diferentes orígenes e intereses y a las tensiones que ello origina. Es el caso de Bryden (2000 y 2001), quien señala que las personas que se trasladan al medio rural con objetivos exclusivamente residenciales, pueden cuestionar algunos aspectos de la actividad agropecuaria, como ruidos y olores desagradables.

Holmes (2006) considera que la tensión entre diferentes alternativas de uso del espacio rural adquiere preeminencia en países como el Reino Unido, caracterizados por una baja disponibilidad de tierras. Asimismo, niveles de ingreso per cápita elevados aumentan las posibilidades de formas "posfordistas" de consumo de lo rural. En cambio, donde la oferta de tierras es mayor los conflictos adquieren un carácter más localizado o presentan menor envergadura. En el caso argentino, la importancia que reviste la actividad agraria en la producción de alimentos básicos y en la generación de divisas explicaría que los conflictos asociados con diferentes modalidades productivas y con los agentes que las encarnan presenten mayor magnitud que las tensiones entre el uso productivo y el residencial. Sin embargo, es pertinente recuperar la diferenciación espacial en el análisis: en determinadas áreas, esta última tensión puede adquirir una expresión particular.

Adoptemos una u otra visión, queda claro que las diferentes y más complejas demandas sociales están generando profundas transformaciones en los espacios rurales. La ponderación de los efectos que generan estos nuevos desarrollos y actividades dependerá de si se consideran aspectos exclusivamente sectoriales o si la mirada se amplía hacia lo territorial.

Es en los ámbitos locales, que poseen formas de inserción específicas en el espacio regional históricamente determinadas, donde estos procesos y dinámicas pueden visualizarse con mayor nitidez, como se verá en el siguiente apartado.

2006), para dar cuenta del giro desde las metas puramente productivas hacia un mix más complejo que abarca producción, consumo y preservación. Se recuerda que a lo largo de la historia, el uso de los recursos por parte del hombre combinó estos tres diferentes propósitos, evidenciando el siglo xx una distorsión en favor de lo netamente productivo. 


\title{
2. El caso del partido de Exaltación de la Cruz en la Provincia de Buenos Aires
}

Las zonas perimetropolitanas son particularmente interesantes para el análisis de las tensiones entre diferentes modalidades de uso del suelo. Estas zonas se caracterizan por su accesibilidad, el precio elevado de la tierra, la intensa competencia entre los valores de producción, consumo y preservación, y la necesidad de establecer formas de regulación del espacio (véase cuadro 1).

\section{Cuadro 1 \\ Rasgos básicos de la zona perimetropolitana}

\begin{abstract}
Incidencia
Area de tamaño irregular, generalmente a unos 30 minutos de viaje desde el límite de la ciudad, con prolongaciones que alcanzan los 60 minutos de viaje. La extensión del área es proporcional al tamaño de la población y la riqueza de la ciudad; también está influida por los valores de "amenidad" adjudicados a esta zona.
\end{abstract}

\section{Fuerzas intervinientes}

Vinculadas directamente con la demanda metropolitana inmediata, en especial las siguientes:

- Extracción de recursos y disposición de residuos.

- Producción agrícola: horticultura orientada al mercado.

- Consumo: rural-residencial, actividades recreacionales.

- Servicios: corredores de servicios y otra infraestructura para el transporte.

\section{Atributos centrales}

- Alta accesibilidad a las áreas metropolitanas.

- Valores elevados de la tierra con fines tanto productivos como de consumo

- Mercados de tierra múltiples, con incrementos favorecidos por inversiones especulativas que buscan ganancias a partir de cambios en los usos de la tierra.

- Altas inversiones en infraestructura.

- Heterogeneidad y conflicto a escala local, especialmente en las áreas que experimentan cambios rápidos.

- Necesidad de regulación del espacio rural, con especificación de los usos permitidos según zonas.

\section{Trayectorias}

- Complejidad en el ámbito local, con trayectorias marcadamente diferentes, frecuentemente guiadas por los esquemas de zonificación y reflejadas en diferentes valores de la tierra.

- Marcada diferenciación entre y dentro de las zonas orientadas al consumo y la producción.

Fuente: Elaboración propia con base en Holmes, 2005. 


\section{Mapa 1}

Ubicación del partido de Exaltación de la Cruz, en la provincia de Buenos Aires

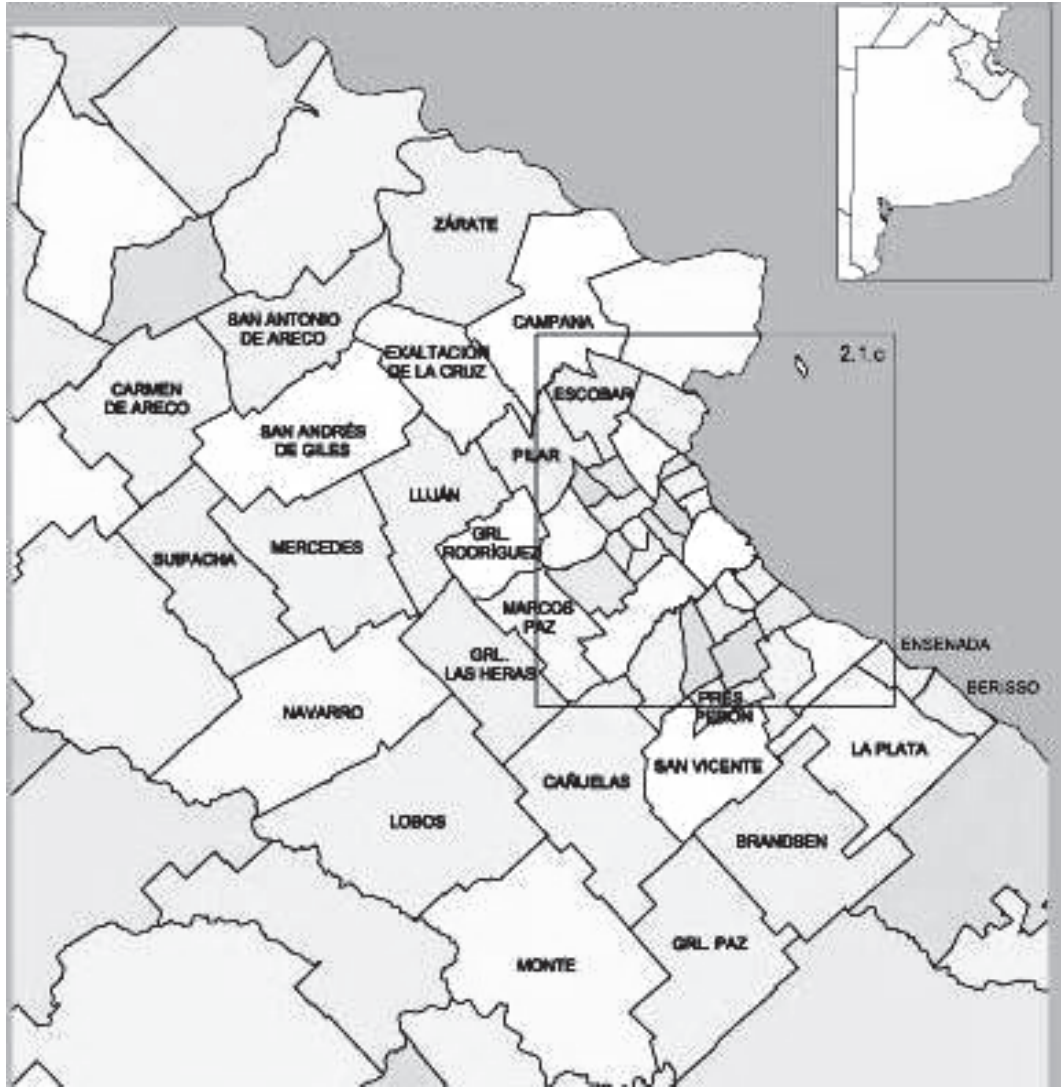

Fuente. INDEC, 2001.

Estas zonas se distinguen asimismo por la diversidad de actores sociales intervinientes. En una primera aproximación podemos categorizarlos como locales, "neolocales" (es decir, de instalación reciente) o bien extralocales -aunque con capacidad de influir en los ámbitos rurales en cuestión. Una caracterización más precisa de los actores debiera poder diferenciarlos en virtud de su acceso a diferentes capitales, incluyendo la amplitud y densidad de las redes sociales en las que participan, ya que si bien algunos pueden ser caracterizados como locales en función de su lugar de residencia y ejercicio de sus ocupaciones, poseen conexiones o fuentes de información que pueden exceder con creces el ámbito local. 
El partido de Exaltación de la Cruz, en la Provincia de Buenos Aires, se inscribe particularmente en las dinámicas "neorrurales" mencionadas. Ubicado a $80 \mathrm{~km}$ de la ciudad de Buenos Aires, presenta una buena conectividad con ella a través de las vías "rápidas" 8 y 9. Desde comienzos de la década del noventa, el patrimonio histórico-cultural de su localidad cabecera, Capilla del Señor, ha sido objeto de una revalorización, materializándose en 1994 la declaración del mismo como "Bien Histórico Nacional", lo que se tradujo en acciones locales de preservación. ${ }^{6}$ La localidad cuenta con afluencia de visitantes durante los fines de semana, y algunos de ellos concurren a los establecimientos de turismo rural ubicados en el partido.

Asimismo, a lo largo de la década, y como parte de los procesos que aquí se describen, han ido cobrando fuerte impulso en el área las urbanizaciones destinadas a sectores de origen extralocal y con ingresos relativamente elevados. La expectativa inmobiliaria llevó al incremento del valor de la tierra, particularmente en las parcelas cuya extensión es de mediana a chica, que presentan buenos accesos y cercanía con la ciudad de Buenos Aires. Esas urbanizaciones cerradas se desarrollaron casi en paralelo a emprendimientos de vivienda social destinados a sectores de bajos ingresos y encarados por el municipio, lo que agrega mayor complejidad a la dinámica de "nuevos usos" de lo rural que estamos analizando.

Tomando el conjunto de partidos del Gran Buenos Aires, y considerando la superficie ocupada a fines de la década por las urbanizaciones cerradas (Chiozza et al., 1999; Torres, 2001), se observa que la zona norte lidera el crecimiento, con el partido de Pilar a la cabeza -para esa fecha contaba con 104 emprendimientos. Exaltación de la Cruz, próximo a este partido, se encuentra en tercer lugar en cuanto a superficie ocupada. ${ }^{7}$ Las nuevas formas de asentamiento dejan de estar ligadas a las vías

${ }^{6}$ El 23 de noviembre de 1991 se constituyó la Asociación Pro Memoria, que define entre sus objetivos el de rescatar y difundir la memoria de hechos y lugares de Capilla del Señor como pueblo histórico, así como promover la conservación, protección, utilización y puesta en valor de su patrimonio cultural. Asimismo, el gobierno municipal inició una serie de acciones tendentes a la preservación de las características del sector urbano de Capilla del Señor (Ordenanza 46 del 20/12/97). La normativa de protección fue incorporada en el Código de Planeamiento Territorial del partido (La Voz de Zárate on line, 23/2/05).

${ }^{7}$ Si bien los trabajos citados no coinciden en cuanto a los datos de la superficie adjudicada a estos emprendimientos -por las distintas fuentes a que recurrieron para estimarla-, ubican a este partido en tercer lugar respecto a los restantes partidos de la periferia en cuanto a la importancia de las urbanizaciones en función de la superficie ocupada. 
ferroviarias, y ahora es la cercanía a las autopistas la que se vuelve determinante en la localización.

Sin embargo, más allá de la relativa novedad del fenómeno, cabe consignar que los vínculos entre lo rural y lo urbano son de larga data en el partido de Exaltación de la Cruz . En las entrevistas a informantes clave se hace referencia a cómo la disponibilidad del ferrocarril facilitaba la residencia en el partido de personas que concurrían diariamente a trabajar a la ciudad de Buenos Aires, lo que mermó luego con la menor disponibilidad de servicios ferroviarios. También se pone de manifiesto la importancia del segmento de propietarios de parcelas de campo que no residían en el partido y concurrían los fines de semana a sus explotaciones. Pero en esa etapa previa, no existía la correlación de fuerzas ligada a lo inmobiliario-residencial que cobraría magnitud luego.

En la década de los noventa se verificaron importantes cambios demográficos en el partido. Por una parte, se incrementó la población total en $40 \%$ a partir de dos fenómenos concurrentes: por un lado, la llegada de pobladores del conurbano bonaerense a los nuevos emprendimientos residenciales, y, por otro, la instalación de trabajadores de las provincias vecinas del litoral, algunos de los cuales llegaron para ocuparse en tareas demandadas por esos emprendimientos y, en otros casos, en actividades agropecuarias. (Craviotti et al., 2005) El segundo de los fenómenos sería el más relevante desde el punto de vista del impacto poblacional.

Se observa asimismo un fuerte corte espacial en la expansión residencial. Los cuarteles III y IV del partido, al sur del Arroyo de la Cruz, son los que experimentaron mayores cambios. La población se incrementa en mayor medida en las localidades que presentan mejor conectividad y mayor cercanía respecto a la ciudad de Buenos Aires. La ciudad cabecera, Capilla del Señor, crece proporcionalmente menos por encontrarse relativamente alejada de las vías rápidas (véase cuadro 2), registrando asimismo menor concentración de la población de lo que suele ser frecuente en otros partidos de la región pampeana argentina.

Asimismo, si bien la población rural decreció en valores relativos respecto de la urbana, aumentó en números absolutos durante el periodo analizado. Es interesante mencionar que, según los datos censales, el partido muestra una pirámide demográfica parecida a la de los partidos del conurbano, donde es importante la población joven. 
Cuadro 2

Evolución de la población del partido de Exaltación de la Cruz por localidades

\begin{tabular}{lrrc}
\hline Localidad & 1991 & 2001 & $\begin{array}{c}\text { \% de variación } \\
\text { intercensal }\end{array}$ \\
\hline Capilla del Señor & 6,173 & 8,044 & 30.3 \\
Los Cardales & 3,528 & 5,342 & 51.4 \\
Robles-Pavón & 2,332 & 4,761 & 104 \\
Parada Orlando & 698 & 527 & -24.4 \\
Diego Gaynor & 241 & 198 & -17.8 \\
Arroyo de la Cruz & 103 & 185 & 80 \\
Total de población del partido & 17,072 & 24,167 & 41.6 \\
\hline
\end{tabular}

Fuente: Elaboración propia en base a datos del Censo Nacional de Población, Hogares y Viviendas (1991 y 2001).

En ello puede tener que ver la afluencia de migrantes provenientes de las provincias del Noreste argentino, con familias numerosas, así como la composición demográfica que caracteriza a las urbanizaciones cerradas. En efecto, en este tipo de emprendimientos predominan los matrimonios con hijos pequeños (Svampa y González-Bombal, 2001). Si se comparan las localidades del partido que son eje de la expansión inmobiliaria-Parada Robles y Los Cardales- con Capilla del Señor, se aprecian las diferencias existentes en cuanto a la composición etaria de la población (véase cuadro 3).

Un aspecto que también refleja las diferencias entre localidades es la estructura ocupacional de la población. La expansión de los usos residenciales del suelo y la consiguiente demanda de

\section{Cuadro 3}

Composición etaria de la población en las principales localidades del partido de Exaltación de la Cruz, (porcentajes)

\begin{tabular}{lccc}
\hline Localidad & $\begin{array}{c}\text { Menores } \\
\text { de } 15 \text { años }\end{array}$ & $\begin{array}{c}\text { De } 15 \text { a } \\
64 \text { años }\end{array}$ & $\begin{array}{c}65 \text { y } \\
\text { más años }\end{array}$ \\
\hline Capilla del Señor & 27.9 & 60.5 & 11.5 \\
Los Cardales & 29.5 & 62.8 & 7.6 \\
Robles-Pavón & 27.8 & 64.1 & 8.0 \\
Total de población del partido & 29.7 & 61.6 & 8.7 \\
\hline
\end{tabular}

Fuente: Elaboración propia en base a datos del Censo Nacional de Población, Hogares y Viviendas (2001). 


\section{Cuadro 4}

Estructura ocupacional de la población de 14 años y más en las principales localidades del partido de Exaltación de la Cruz (porcentajes)

\begin{tabular}{lccc}
\hline Localidad & Ocupados & Desocupados & Inactivos \\
\hline Capilla del Señor & 45.4 & 15.7 & 38.8 \\
Los Cardales & 53.3 & 11.7 & 34.9 \\
Robles-Pavón & 53.5 & 11.1 & 35.4 \\
\hline
\end{tabular}

\begin{tabular}{lcccc}
\hline & $\begin{array}{c}\text { Obreroso } \\
\text { empleados }\end{array}$ & Patrones & $\begin{array}{c}\text { Trab.por } \\
\text { cta.propia }\end{array}$ & $\begin{array}{c}\text { Trab. } \\
\text { familiares }\end{array}$ \\
\hline Capilla del Señor & 71.3 & 7.4 & 18.4 & 2.8 \\
Los Cardales & 63.6 & 10.5 & 24.1 & 1.7 \\
Robles-Pavón & 62.1 & 8.8 & 26.2 & 2.8 \\
\hline
\end{tabular}

Fuente: Elaboración propia en base a datos del Censo Nacional de Población, Hogares y Viviendas (2001).

servicios personales se expresan en una mayor proporción de ocupados y, dentro de ellos, de trabajadores por cuenta propia, en Los Cardales y Parada Robles respecto a Capilla del Señor (véase cuadro 4).

\subsection{Lo residencial y lo productivo. Las tensiones emergentes}

A pesar de la importancia que cobran las actividades de servicios en el partido, desde el punto de vista tanto económico como del empleo, existen algunas pocas industrias de cierta relevancia y una actividad agraria donde coexisten las actividades extensivas propias de la región pampeana -soja, maíz y trigo, ganaderíacon actividades intensivas -avicultura y horticultura- y ciertas actividades innovadoras. ${ }^{8}$

Desde el punto de vista agroproductivo ha habido un proceso importante de cambio en los últimos 60 o 70 años. Históricamente, la zona tuvo importancia como productora de lanares, con ganadería de cría en algunas áreas específicas del partido, para pasar luego a ser un área tambera. A partir de la década de

\footnotetext{
${ }^{8}$ Según el Censo Nacional Agropecuario 2002, en el partido se llevan a cabo cultivos anuales como soja, maíz y trigo en una superficie de 22,872 hectáreas. También existe ganadería en aproximadamente dos terceras partes de las explotaciones, incluyendo grandes establecimientos y unos pocos casos de feed lots, habiéndose agregado en los últimos años producciones innovadoras destinadas fundamentalmente a la exportación, como es el caso de la cunicultura y la producción de arándanos, entre otras.
} 
los setenta se produjo una crisis de esa industria debido a la competencia de las grandes empresas y el desplazamiento de la producción hacia zonas de la provincia de Buenos Aires más aptas para el desarrollo de esa actividad. Así, los tambos fueron substituidos por ganadería vacuna, agricultura y avicultura. "Esta última actividad cobró mucha importancia y gran parte de los productores tamberos se volcó a ella, tanto a la producción de huevos como, fundamentalmente, al engorde de pollos" (Craviotti, et al., 2005).

En el partido o en su cercanía se establecieron medianas y grandes empresas que fueron "integrando" a los pequeños avicultores en las cadenas de producción típicas de este rubro. La producción de cereales en el área, con la cual se elaboraba el alimento balanceado, estimulaba dicha localización. En la década de los ochenta, y más fuertemente durante los años noventa, la actividad decayó y desapareció una importante proporción de productores avícolas. Se retiraron las empresas internacionales y quedaron las nacionales.

La recesión que experimentó la Argentina a partir de 1998 afectó profundamente el conjunto de las actividades del partido. Este proceso desembocó en una crisis político-institucional a fines del 2001 a partir de la cual se modificaron las reglas de juego en el campo económico. De la mano de la marcada devaluación de la moneda a principios del 2002, y acompañando la tendencia general del país, se reposicionaron las actividades agrarias orientadas a la exportación desarrolladas en el partido.

La avicultura también experimentó un importante repunte. La industria había aprovechado la paridad cambiaria un peso- un dólar vigente en los noventa para modernizar sus bienes de capital, pero el ingreso de pollos desde Brasil, uno de los principales exportadores, y la recesión luego pusieron en jaque a la avicultura local. Dos importantes empresas integradoras, que compraban $50 \%$ de los pollos del partido, quebraron a fines de los noventa, y dejaron de pagar a los productores. Durante varios años, las granjas menos equipadas dejaron de producir o lo hicieron por su cuenta, recurriendo a modalidades precarias de comercialización para poder subsistir. ${ }^{9}$

9 “[...] justo fue que San Sebastián presentó quiebra y dejaron todas las granjas a la deriva, San Sebastián tenía muchas granjas, entonces Tres Arroyos tomó las granjas mejores, sobre ruta, de San Sebastián, y las granjas de tierra las fue dejando [...] La excusa era la tierra, empezó la crisis y bueno... esas granjas no le quedaron a nadie, estaban a la deriva, a veces venía una empresa chiquita y te ofrecía un galpón, yo tuve 
La devaluación, y un poco más tarde la aparición de la influenza aviar en Asia, posibilitaron un fuerte incremento de las exportaciones argentinas de productos avícolas, mismas que en el 2005 registraron ventas 123 millones de dólares en 78 mercados. Una cierta recuperación del consumo interno con posterioridad al 2002 hizo el resto. Frente a este panorama se ampliaron las instalaciones en las plantas de faena y de los criaderos de pollos. Un representante de la industria indicaba recientemente que "el principal obstáculo hoy es la construcción de galpones de cría en las granjas" (La Nación, 1/10/05). Existe una fuerte demanda de galpones, pero no hay oferta.

Al tiempo que se modificaron fuertemente las condiciones de rentabilidad de las actividades agrarias, los emprendimientos residenciales volvieron a tomar cierto impulso, pero redefinido, y adquirieron características más selectivas. Si la recesión previa no había afectado en forma decisiva a ciertos "megaemprendimientos" puestos en marcha en la zona norte del Gran Buenos Aires, la reactivación posterior mostró la preferencia de la demanda por emprendimientos con buena accesibilidad y disponibilidad de servicios, destacándose el caso de Nordelta -que cuenta con 1,600 hectáreas y alberga en su interior 20 barrios privados. Esto explica por qué en Exaltación de la Cruz no existen proyectos de barrios nuevos. En Capilla del Señor en particular, la venta de lotes y la construcción de casas fueron menores a las previsiones iniciales.

Esta situación de dinamismo selectivo de lo residencial y reactivación de las actividades agrarias orientadas a la exportación derivó en una paradoja en el partido de Exaltación de la Cruz, que había establecido un andamiaje legal para acompañar y favorecer la expansión de los emprendimientos residenciales a partir de la competencia que le confieren las leyes provinciales. ${ }^{10}$

un galpón solo, tenía cuatro y trabajaba con uno. [...] Gente que tenía granjas y se quedó sin pollos, lo único que sabían hacer era criar pollos, compraban algunos вв у después los vendían en el pueblo" (Entrevista a productor, Caso núm. 3, 2005).

${ }^{10}$ Las regulaciones vigentes en la provincia de Buenos Aires otorgan competencia primaria a los municipios en el ordenamiento territorial, aunque la normativa debe ser convalidada por el Ejecutivo provincial (Decreto- ley 8912/77 de la provincia de Buenos Aires). Este decreto contiene precisiones relativas al uso del suelo, la subdivisión, la ocupación y el equipamiento de las áreas urbanas y extraurbanas. Por primera vez establece la figura de los clubes de campo y las normas para su instalación, las que fueron ampliadas luego con el decreto 8404/86. Con el decreto 27/98 fueron regulados los barrios cerrados. Para el resto de la tipología de urbanizaciones cerradas, no existe aún normativa específica (Carballo, 2005). 
En efecto, en el contexto de alza de los desarrollos inmobiliarios, y de estancamiento o aun involución de las actividades agrarias del partido, el municipio sancionó en 1997 una ordenanza de uso del suelo (o código de planeamiento territorial) que desde sus propios fundamentos favorecía ese tipo de asentamientos y colocaba en un segundo plano otras actividades características del medio rural -las actividades agrarias-, a las que consideraba como negativas desde el punto de vista del empleo.

El partido de Exaltación cuenta con dos localidades principales, Capilla del Señor y Los Cardales; tres pequeños poblados de baja ocupación, Diego Gaynor, Pavón y Robles, y un relativamente importante número, en extensión y cantidad, de parcelamientos de tipo urbano dispersos y no siempre materializados o con escasísima ocupación, además de una extensa área residencial extraurbana con diverso grado de consolidación, insertos en un área rural destinada a la producción agrícola ganadera próxima al Área Metropolitana Buenos Aires (АMBA). Esta actividad, que genera pocos empleos rurales y es de bajo efecto multiplicador en industria y comercio, y la ubicación del partido entre sistemas urbanos de jerarquía nacional y regional con los que por su escasa accesibilidad establece pocas relaciones funcionales, ha restringido su desarrollo.

[...] el mejoramiento de las vinculaciones regionales, nacionales y con el Mercosur de Exaltación de la Cruz en general y de Capilla del Señor en particular, debido a las obras de pavimentación vial y reactivación ferroviaria encaradas en los últimos años, favorecerán su inserción en sistemas urbanos más dinámicos y con ello la generación de funciones alternativas que aprovechen esta accesibilidad. (prólogo de la Ordenanza 60 del 8/12/97).

Esta nueva ordenanza, además de clasificar vastas áreas del partido como residenciales exclusivas, especifica claramente los usos del suelo permitidos en las diferentes áreas, a tono con los ordenamientos más actuales en la materia. Respecto a las actividades productivas, preserva los intereses de las principales industrias ya instaladas -cuyas áreas de emplazamiento son calificadas como "precintos industriales", acotadas a su actual extensión-, pero no ocurre lo propio con algunas actividades agropecuarias intensivas: actividades como floricultura, horticultura, silvicultura, vivero, apicultura y criaderos de conejos, cerdos y aves, sólo pueden instalarse en la zona agropecuaria siempre que estén a más de mil metros de sectores ocupados o destinados a vivienda. Esta distinción es importante, porque el hecho de que un pro- 
yecto habitacional cuente con la aprobación del municipio supone una restricción para el ejercicio de estas actividades aunque transcurra el tiempo y no se hayan iniciado las obras.

El carácter restrictivo del código territorial también afectó a las actividades comerciales del partido. Sin embargo, como señalan informantes clave vinculados al municipio, "al quedar planchada la actividad inmobiliaria, la zonificación es un tope para que sigan creciendo las otras". "La situación en el 97 era una y otra en el 2000. La gente necesitaba subsistir, tener comercios diarios en los barrios o hacer explotaciones intensivas en parcelas dedicadas a la residencia” (Entrevistas a informantes clave, 2005).

Las quejas propiciaron algunos ajustes en la normativa. Los cambios introducidos permitieron que en la zona residencial exclusiva se instalaran los comercios minoristas; asimismo, las parcelas que fueron zonificadas como residenciales extraurbanas o "de reserva para ampliación urbana", podían ser destinadas a algunos usos agropecuarios intensivos (como horticultura y viveros) si no formaban parte de barrios ya constituidos. Sin embargo, se mantuvo vigente la prohibición de instalar apiarios y criaderos de aves, cerdos y conejos, a menos de mil metros de sectores ocupados o destinados a vivienda (Ordenanza sancionada por el Consejo Deliberante el 10/12/04).

Según indican varios estudios (Chiozza et al., 1999; Carballo, 2005), la expansión de los usos residenciales viene impulsada por la iniciativa privada, fundamentalmente por los desarrolladores inmobiliarios. Las normativas llegan en muchos casos después de consumada la expansión de las urbanizaciones. Los municipios enfrentan límites para regular ese proceso y, salvo excepciones, lo favorecen, debido a sus impactos sobre el empleo y sobre las exiguas arcas municipales (Svampa, 2001). Desde esta perspectiva, resultaría manifiesta la debilidad de los actores sociales locales frente a los recursos -no sólo económicos, sino también en términos de vinculaciones sociales- que poseen los agentes externos, básicamente los inversores inmobiliarios.

En el caso del partido de Exaltación de la Cruz, la visión que estaba detrás del nuevo ordenamiento territorial era que los countries y barrios privados constituían industrias sin chimenea, por lo que había que fomentar su localización en el partido. Se pensaba en aprovechar la presunta "saturación" del cercano partido

${ }^{11}$ Sin embargo, el municipio fomentó actividades productivas con el fin de atender la situación de los sectores de bajos ingresos generada a partir de la crisis del 2001. Inició un emprendimiento agropecuario en un predio de 33 hectáreas, llamado "El 
de Pilar, evitando cometer los “errores” en que éste había incurrido por falta de planificación. ${ }^{11}$

Sin embargo, son los procesos macroeconómicos más que las regulaciones, los que terminan configurando los usos del suelo, aunque estas últimas influyen en la intensidad y ritmo del proceso. No necesariamente los promotores del uso residencial del suelo rural son exclusivamente de origen extralocal: muchas veces se produce la convergencia de los actores externos con actores locales que poseen intereses directos en los nuevos emprendimientos residenciales.

\subsection{La avicultura como expresión de las tensiones entre la "nueva" y la "vieja" ruralidad}

Como indicáramos anteriormente, en el contexto del fuerte crecimiento de las urbanizaciones cerradas que caracterizó a la primera mitad de los años noventa, el partido optó por un perfil residencial. Ciertas actividades agropecuarias intensivas como la avicultura y la cunicultura fueron catalogadas localmente como incompatibles con esos desarrollos, y fue prohibido su emplazamiento en cercanía de urbanizaciones actuales o proyectadas.

Siguiendo los postulados del código territorial, el municipio sancionó normas específicas tendentes a la relocalización de los establecimientos avícolas que existían en el partido. Inicialmente previó plazos prolongados y flexibilizó la distancia considerada perjudicial para los vecinos. ${ }^{12}$ El resurgimiento de la avicultura con posterioridad al 2002 y el hecho de que no se verificaran traslados de granjas, indujeron al endurecimiento de los plazos

Corralito", en el que instaló una quinta de verduras, un tambo, un criadero de conejos, gallinas ponedoras, pollos parrilleros, frutales. Los vecinos colaboraron con equipamiento en desuso. En la actualidad, el emprendimiento sigue funcionando, y en él trabajan beneficiarios de planes sociales. Lo producido se destina a la propia gente y a los comedores escolares. Sin embargo, la idea es desarmarlo, ya que en la visión de los funcionarios locales "a la Municipalidad le sale igual producir que comprar, es complicado mantenerlo, la gente de los planes no quiere trabajar" (Entrevista a informante clave, 2005).

${ }^{12}$ La Ordenanza 38 del 22/9/98 establecía un plazo máximo de cuatro años para la regularización de la localización de los establecimientos avícolas que no se encontraran en zona rural. Esta norma flexibilizó la aplicación de la Ley de Ordenamiento Territorial de 1997, ya que consideró que debían trasladarse las granjas que no estuvieran ubicadas a una distancia mínima de 300 metros (en vez de mil) y exceptuó de la exigencia a las que hubieran sido habilitadas con anterioridad a dicha ley. La Ordenanza 80 del 23/10/02 prorrogó por dos años el plazo para la relocalización de los establecimientos.

${ }^{13}$ La Ordenanza 93 del 21/12/04 estableció un cronograma para la relocalización de establecimientos que se encontraran a menos de mil metros de núcleos habitaciona- 
para la relocalización y de acciones concretas por parte del municipio. ${ }^{13}$ Se enviaron notificaciones a los infractores y en ciertos casos se aplicaron multas; sin embargo, las alternativas para los afectados son escasas. Los galpones avícolas tienen un costo elevado (unos 30,000 dólares), y no se pueden desarmar y armar en otro lugar. Además, "tampoco se sabe adónde ir. Los lugares con extensiones chicas están zonificados como residenciales”. Los propietarios de campos prefieren no vender parte de los mismos a un granjero, porque después tienen dificultades para vender los otros lotes (Entrevistas a informantes clave, 2005).

Según una estadística municipal del año 2005, existen en el partido 72 establecimientos avícolas (que reúnen unos 307 galpones), de los cuales solamente $31 \%$ se encuentra en zonas donde este tipo de actividad es permitida. Más de la mitad estaría funcionando con habilitaciones provisorias o directamente sin habilitación. Existen variantes según el área considerada, pero todos los cuarteles del partido, excepto uno, presentan situaciones problemáticas dada la zonificación de vastas áreas como residenciales exclusivas.

A diferencia de otras actividades agrarias, la avicultura posee una fuerte tradición local y es desarrollada fundamentalmente por residentes del partido, tal como se deduce de las entrevistas realizadas. ${ }^{14}$ Las sucesivas crisis redujeron el número de granjeros, y los sobrevivientes compensaron los magros ingresos provenientes de la avicultura con otras actividades productivas o extraprediales, o bien intentaron aumentar la escala de producción con el objetivo de licuar costos fijos. Aunque a distinto ritmo, todos han ido incorporando mejoras tecnológicas (en el caso de la producción de parrilleros, bebederos automáticos y ventilación en los galpones). Se tiende a la automatización del conjunto de las actividades con la incorporación de comederos automáticos, aunque son pocos los productores que lo han hecho en forma total. Se trata de una mejora tecnológica demandada por las empresas que tiene un impacto significativo sobre la mano de

les. El plazo para la relocalización variaba de acuerdo con la cantidad de población que dichos núcleos presentaran (oscilaba entre 90 y 365 días). La norma facultaba al Departamento Ejecutivo a establecer excepciones siempre que no se opusieran al menos $35 \%$ de los vecinos del núcleo habitacional de influencia.

${ }^{14}$ Se efectuaron nueve entrevistas a avicultores (12\% del total); dos de ellos con gallinas ponedoras, y el resto, productores de pollos parrilleros de diferentes escalas productivas (dos productores chicos, tres medianos y dos grandes). La capacidad productiva de estos últimos oscila entre 20,000 y 160,000 pollos por crianza, y cuentan con instalaciones de entre dos y 12 galpones. 
obra empleada en forma permanente en los establecimientos (Gavidia et al., 2001).

La mayoría de los avicultores entrevistados se dedica exclusivamente a la producción avícola. La realización de otras actividades en el predio se encuentra condicionada por la baja superficie que controla, que sólo en un caso supera las diez hectáreas. La forma de producción es empresarial pura, y en el caso de los productores más chicos, combina el trabajo familiar con la contratación de un trabajador permanente o eventuales. En todos los casos es importante el rol del productor en la supervisión de las actividades, si bien los productores integrados han renunciado a la autonomía del productor clásico en pos del seguimiento de las pautas establecidas por las empresas. Su vínculo con alguna de las empresas que operan en el partido -dos de las cuales presentan relevancia nacional- carece de contrato formal y de certeza respecto de la cantidad de crianzas al año. Esta última cuestión, junto con la eficiencia productiva, se transforma en el principal regulador del ingreso a obtener de la actividad. ${ }^{15}$

La iniciativa municipal de la relocalización de la granjas ha propiciado conflictos manifiestos, donde en uno de los polos se encuentran los avicultores, algunos de los cuales han presentado notas al intendente o efectuado presentaciones judiciales, y en otro, la municipalidad. No existe un encuadre institucional de los actores -en el caso de los avicultores, no pertenecen a ninguna organización específica- ni tampoco está claro quiénes y cuántos respaldan las diferentes posiciones, si bien unos y otros se escudan en el apoyo de los vecinos.

La orientación productiva del establecimiento (cría de pollos o producción de huevos) y, fundamentalmente, el origen y la ocupación de los vecinos, influirían en la percepción de las "molestias" adjudicadas a la actividad avícola, dando cuenta de las diferentes representaciones de la ruralidad a las que hacíamos referencia en el apartado teórico. Como señala un funcionario local, la localidad de Diego Gaynor también está zonificada como residencial; se trata de un pequeño poblado de alrededor de 200 habitantes, pero en este caso "hay menos problemas porque la gente ha nacido ahí y los galpones forman parte de su paisaje." Asimismo, algunos de los residentes en los barrios construidos

${ }^{15}$ Se determina el precio por pollo que sale del galpón a partir de la combinación de variables -como la mortandad, la conversión $(\mathrm{kg}$. de alimento necesario para lograr un $\mathrm{kg}$. de pollo), el peso promedio y la edad de los pollos, en una formula llamada Índice de Eficiencia Europea (Gavidia et al., 2001). 
por el municipio también trabajan en las granjas, y es frecuente que tengan producción de autoconsumo. "Entramos en un sector de sombras. ¿Hasta dónde el municipio llevaría un control tan exhaustivo? No lo hemos hecho, en general no hay quejas pero nunca falta una persona de otro lado que compre un lote, una propiedad y le moleste. En cambio uno, como es nacido y criado acá está más acostumbrado a convivir con este tipo de naturaleza" (Entrevista, 2005).

Esta expresión, "nacido y criado", aparece en varias de las entrevistas realizadas; sin embargo, el "clivaje" local-extralocal en el conflicto no es tan claro, como se deduce del testimonio anterior. Ciertas granjas se encuentran "alambre de por medio" con barrios municipales, y algunos vecinos habrían manifestado su inquietud, aunque no necesariamente reclamando trasladarlas. La coexistencia de la avicultura y los barrios municipales data de varios años en el partido, pero la repentina preocupación por la cuestión genera suspicacias sobre los verdaderos intereses que subyacen trás la tentativa de relocalización. "A mí me notificaron que no estoy a más de mil metros de un barrio, yo estoy en zona rural y al barrio lo construyeron políticamente hace años y estará a unos 700 metros, pero los olores que emana no perjudican en 30 años que estoy con la avicultura" (Entrevista a productor, Caso núm. 6).

Frente a las tensiones descritas, los avicultores no se plantean abandonar la actividad productiva y vender sus parcelas para destinarlas a emprendimientos inmobiliarios, dadas las inversiones efectuadas y por el hecho de que la avicultura constituye, en la mayor parte de los casos, su única actividad. ${ }^{16}$ La mayoría coincide en que en ciertos casos es necesaria la relocalización de las granjas, pero también en que el municipio debe colaborar en la búsqueda y la instrumentación de una alternativa. Asimismo, consideran que debe apoyarse al conjunto de las actividades del partido, ya que los efectos benéficos de los emprendimientos residenciales destinados a sectores de altos ingresos son limitados, al menos para la localidad de Capilla del Señor:

Acá se quiso fomentar emprendimientos de la industria sin chimenea, eso fue lo que manifestaron las autoridades, los loteos para que la

16 “[...] el pretexto de la municipalidad, cuando fuimos uno por uno a decir:,'¿Qué es esto?', en el fondo te decían: '¿Vos sabés el capital que tenés en tierras?'. 'No me importa, yo en ese campo quiero tener galpones de pollos, no quiero venderlo para hacer un barrio privado" (Entrevista a productor, 2005, Caso núm.4). 
gente venga a construir y residir acá, después del freno que hubo en todo lo que es construcción eso quedó bastante marginado. Hay muchos emprendimientos de loteos pero no se nota en el pueblo que se hayan vendido una cantidad muy importante de lotes. No se nota el movimiento comercial tampoco (Entrevista a productor, Caso núm. 6).

No sé si los countries son un buen adelanto para Capilla, es un pueblo tan chico. No creo que generen mucho empleo porque las casas se utilizan el fin de semana. (Entrevista a productor, Caso núm.1).

[...] la idea política es que fábricas no, sí countries y barrios cerrados que también van a fomentar mano de obra, pero la mayoría de la gente que viene a estos barrios cerrados es de afuera, no son del pueblo y por lo general ellos traen su personal. (Entrevista a productor, Caso núm. 3).

Acá han loteado lotes de 200 hectáreas y hay 10 casas, ¿qué puede dar de productivo al pueblo? Nada. [...] Es impacto a largo plazo. (Entrevista a productor, Caso Núm. 7).

La coexistencia de actividades productivas y residenciales se manifiesta de manera clara en el partido analizado, que se encuentra lo suficientemente cercano a la ciudad de Buenos Aires como para pensar en el crecimiento de las urbanizaciones cerradas y otras formas de hábitat, pero carece de los atributos que facilitarían el predominio de lo inmobiliario por sobre otros usos alternativos del suelo, en un contexto en el que la demanda se ha vuelto más selectiva.

Lo particular acá es que estamos en una etapa de transición. Lo decíamos el otro día con un amigo veterinario, no estamos para ocuparnos del campo ni de animales pequeños. [...] No todos [los municipios] tienen un código de planeamiento. San Antonio de Areco y San Andrés de Giles son más libres. Tampoco esto es Pilar que tomó un perfil. Ahí vas a poner una explotación de conejos y te piden de todo. (Entrevista a funcionario municipal, 2005).

Para ser un partido residencial creo que le falta un poco. [...] El partido está empezando a darse vuelta en forma turística, pero va a tardar bastante, todavía en la parte de campos hay de 700, mil hectáreas. Todavía es un partido productivo. (Entrevista a productor, Caso núm. $8,2005)$.

Es un partido quedado a mitad de camino, no es ni una cosa ni la otra, no es urbano ni rural (Entrevista a informante. clave, dueño de un establecimiento de turismo rural, 2005).

Entonces, si el proceso de expansión de los emprendimientos en la zona norte del área perimetropolitana se tradujo en iniciativas 
de algunos actores optando por un perfil de desarrollo local determinado y procurando "acelerar los tiempos" de la transición, la evolución socioeconómica del país puso en cuestión una opción tan definida. Se genera así la necesidad de nuevas formas de regulación local que tengan en cuenta las necesidades del conjunto de los actores.

\section{Conclusiones}

En el análisis previo se procuró avanzar en lo relativo al impacto que genera la expansión de emprendimientos residenciales en el medio rural desde el punto de vista de las actividades y los actores preexistentes. Se profundizó en los vínculos entre lo rural y lo urbano analizando las tensiones que se producen entre algunas actividades productivas y las neorurales, materializadas tanto en emprendimientos habitacionales destinados a sectores de ingresos elevados, como en barrios municipales destinados a población de bajos recursos.

La perspectiva adoptada hizo foco en el nivel local, procurando visualizar el interjuego real entre fuerzas y actores sociales que se produce en un área determinada, donde la tensión entre actividades y usos alternativos del suelo adquiere particular expresión debido a su relativa cercanía a la ciudad de Buenos Aires. En este ámbito, la importancia de las fuerzas ligadas a lo residencial-inmobiliario se tradujo en instrumentos regulatorios específicos, que afectan a actividades agrarias de fuerte arraigo en la zona.

Sin embargo, no necesariamente el conflicto generado opone actores locales con extralocales; los actores son difusos y también sus alianzas, quizá porque no existen efectos unívocamente positivos o negativos ligados a las diferentes actividades. La temática del empleo es particularmente ilustrativa: la demanda de servicios vinculados a los emprendimientos residenciales se basa principalmente en personal eventual, que se caracteriza por la precariedad laboral. Por su parte, las actividades agropecuarias han experimentado en su mayoría una intensa tecnificación, que las ha convertido en fuertes expulsoras de mano de obra en los últimos años.

Por otro lado, no se observa que la intensificación productiva en el sector agrario obedezca en este caso, a la elevación del precio de la tierra generada por los nuevos usos residenciales, tal como indican algunos estudios previos. En el caso de la avicultura, se trata de una actividad de por sí intensiva; además la gran 
mayoría de los avicultores es propietario de su parcela y se estableció con anterioridad al auge inmobiliario. Es más bien la peculiar relación con la industria integradora y la posibilidad que ésta tiene de transmitir los efectos de las sucesivas crisis al eslabón agrario, la determinante de una mayor intensificación productiva. Distinta puede ser la situación de otras actividades agrarias desarrolladas en pequeñas superficies y que carecen de este vínculo particular, como es el caso de la horticultura.

Una lectura de los procesos analizados desde el punto de vista teórico nos permite señalar que los cambios agroproductivos y la expansión residencial se conjugan para dar lugar a espacios rurales donde la heterogeneidad no sólo persiste, sino que incluso se incrementa. Se generan nuevas configuraciones de actores sociales, y la inserción de éstos se vuelve más compleja. El acceso a recursos no garantiza una posición diferencial, en la medida en que dentro de las franjas "perdedoras" de los procesos de transformación también existen sectores productivos con cierta disponibilidad de capital y de control sobre el trabajo ajeno (pequeños empresarios).

El tipo de tensiones generadas pone de manifiesto la necesidad de nuevas formas de regulación, no sólo en términos de instrumentos sino también de instancias donde participen diferentes actores. Se trata de redefinir los vínculos a veces problemáticos entre la "nueva" y la "vieja" ruralidad, con la búsqueda de compromisos entre las diferentes actividades y actores hoy presentes en los espacios rurales.

\section{Bibliografía}

Acuña, Marvin y Keynor Ruiz (1999), “Contribución del desarrollo turístico sobre el empleo rural no agrícola en Costa Rica", Seminario Internacional sobre desarrollo del empleo rural no agrícola, RIMISP, Centro Latinoamericano para el Desarrollo Rural, Santiago de Chile.

Barros, Claudia, Fernanda González-Maraschio y Federico Villareal (2005), "Actividades rurales y neorrurales en un área de contacto rural-urbano", IV Jornadas de Estudios Agrarios y Agroindustriales, Facultad de Ciencias Económicas, Universidad de Buenos Aires, noviembre. 
Barsky, Andrés (2005) "El periurbano productivo, un espacio en constante transformación. Introducción al estado del debate, con referencias al caso de Buenos Aires", Scripta Nova. Revista electrónica de geografía y ciencias sociales, Universidad de Barcelona, vol. Ix, 194 (36), http:// www.ub.es/geocrit/sn/sn-194-36.htm.

Bryden, John (2000), "Decline? What Decline? A Demographic Revival is being Observed in a Number of Rural Areas", LEADER Magazine, 22, April, [documento HTML en $<$ http://ec.europa.eu/comm/archives/leader2/rural-en/biblio/pop/contents.htm >].

Bryden, John (2001), Changing Worldviews of Agriculture in Europe, and Implications for Farmers, Farm Families and Poli$c y$, The Arkleton Centre for Rural Development Research, University of Aberdeen, Aberdeen.

Carballo, Cristina (2005), "Transformaciones urbanas y segregación: Aportes para el análisis ambiental de Campana, 1950-2000", Revista Theomai, número especial Actas Primeras Jornadas Theomai sobre Sociedad y Desarrollo [documento HTML en < http://revista-theomai.unq.edu.ar /numespecial2005/ar_carballo_numesp2005.htm >].

Craviotti, Clara (2002), "Cambios en las modalidades de trabajo: de la producción agraria a la prestación de servicios turísticos", Revista Estudios del Trabajo, Asociación Argentina de Especialistas en Estudios del Trabajo, Buenos Aires, segundo semestre, 24:117-136.

Craviotti, Clara; Silvia Bardomás; Dora Jiménez y Guillermo Neiman (2005), "Cambios ocupacionales y demográficos asociados a situaciones de nueva ruralidad: El caso de Exaltación de la Cruz, provincia de Buenos Aires", IV Jornadas de Estudios Agrarios y Agroindustriales, Facultad de Ciencias Económicas, Universidad de Buenos Aires, Buenos Aires.

Chiozza, Elena; Cristina Carballo y Natalia Torcchia (1999), "El retroceso de la frontera agraria frente a la expansión de 
la frontera urbana", II Jornadas de Estudios Agrarios y Agroindustriales, Facultad de Ciencias Económicas, Universidad de Buenos Aires, Buenos Aires.

Chiozza, Elena, Cristina Carballo y Natalia Torcchia (2001), "Los paisajes de la agricultura periurbana: desde las tierras de pan llevar a las urbanizaciones cerradas", III Jornadas de Estudios Agrarios y Agroindustriales, Facultad de Ciencias Económicas, Universidad de Buenos Aires, noviembre.

Del Grossi, Mario y José Graziano da Silva (2002), Novo rural Brasileiro: Un abordagem ilustrada, vol I., Paraná, Instituto Agronómico Paraná, Paraná.

Gavidia, Roberto; Patricio Calonge y Marcelo Wittver (2001), "Transformaciones en el mercado de trabajo en las granjas avícolas de pollos parrillleros”, en Susana Aparicio y Roberto Benencia (coords.), Antiguos y nuevos asalariados en el agro argentino, Editorial La Colmena, Buenos Aires, pp. 73-90.

Holmes, John (2006), “Impulses towards a multifunctional transition in rural Australia: gaps in the research agenda", Journal of Rural Studies, 22 (2): 142-160.

INDEC (2001), Censo Nacional de Población, Hogares y Viviendas del año 2001, Instituto Nacional de Estadística y Censos, Buenos Aires [disponible en HTML <http:// www.indec.mecon.gov.ar/censo2001s2_2/ ampliada_index.asp? mode $=04>$ ].

Kay, Cristobal (2005), "Enfoques sobre el desarrollo rural en América Latina y Europa desde mediados del siglo veinte", Seminario Internacional Enfoques y Perspectivas de la Enseñanza del Desarrollo Rural, Bogotá, 31 de agosto y 12 de septiembre.

Marsden, Terry (1998), "New Rural Territories: Regulating the Differentiated Rural Spaces", Journal of Rural Studies, 14 (1): 107-117. 
Martínez, Mónica y Marta Picardi-de Sastre (1999), "Agroturismo, un speciality del sector agropecuario argentino", I Jornadas de Estudios Agrarios y Agroindustriales, Facultad de Ciencias Económicas, Universidad de Buenos Aires, Buenos Aires.

Riella, Alberto y Juan Romero (2003), "Nueva ruralidad y empleo no agrícola en Uruguay", en Mónica Bendini y Norma Steimbreger (comps.), Territorios y organización social de la agricultura, Cuaderno del Grupo de Estudios Sociales Agrarios núm. 4, Editorial La Colmena, Buenos Aires, pp.,157-162.

Svampa, Maristella (2001), Los que ganaron. La vida en los countries y barrios privados, Editorial Biblos, Buenos Aires.

Svampa, Maristella e Inés González-Bombal (2001), Movilidad social ascendente y descendente en las clases medias argentinas: un estudio comparativo, Documento de trabajo núm. 3, Sistema de Información, Monitoreo y Evaluación de Programas Sociales, Buenos Aires.

Torres, Horacio (2001), "Cambios socioterritoriales en Buenos Aires durante la década de 1990”, EURE, Vol. 27, num. 80.

Recibido: 6 de marzo de 2006. Aceptado: 29 de mayo de 2006.

Clara Craviotti es Master en Ciencias Sociales con mención en Estudios Agrarios; (FLACso-Argentina). Actualmente es investigadora del Consejo Nacional de Investigaciones Científicas y Técnicas (CONICET) en el Centro de Estudios de Sociología del Trabajo, Facultad de Ciencias Económicas, Universidad de Buenos Aires, Argentina y Profesora de la Maestría en Estudios Sociales Agrarios, Flacso- Argentina. Su línea de investigación se centra en los Cambios socioterritoriales en áreas rurales argentinas: agentes sociales y nueva ruralidad. Entre sus publicaciones recientes se destacan: "De desafiliaciones y desligamientos: Trayectorias de productores familiares expulsados de la producción en la región pampeana argentina", en coautoría con Carla Gras, Desarrollo Económico, vol. 46, núm. 181. "Entre el campo y la 
ciudad. Desafíos y estrategias de la pluriactividad en el agro”, libro compilado con Guillermo Neiman, Ediciones ciccus, Buenos Aires, 2006; "Constructing new resources: Cooperative, networks and blueberry production in an Argentine local area", Review of International Cooperation, vol. 98, núm. 1. 